\title{
Misunderstanding of Parents about using of Anti-Biotic in Upper Respiratory Tract Infection in Riyadh, Saudi Arabia
}

\author{
Fatimah Adam Alaswad ${ }^{1}$, Faisal Mubarak AlZahrani ${ }^{2}$, Faisal Abdullah Alomani ${ }^{2}$, Nawaf Mohammed \\ Alwohaibi ${ }^{2}$, Ali Ahmed Almaimouni ${ }^{2}$, Abdullah Abdulrahman Almannaa ${ }^{2}$, Abdullah Abdulrahman Bin \\ Saeed $^{2}$, Abdulaziz Abdullah Alzwaid ${ }^{2}$, Rakan Abdulrahman Aladwanie ${ }^{2}$ \\ ${ }^{1}$ Ras Tanura General Hospital, Ras Tanura, ${ }^{2}$ Almaarefa Colleges, Riyadh, Saudi Arabia \\ Corresponding Author: Fatimah Adam Alaswad, E-mail; drsuker@hotmail.com
}

\begin{abstract}
Background: Misuse of antibiotics has become a global public health issue for several reasons, one of which is the rapid development of antibiotic resistance that leads to high morbidity and mortality.

Objectives: Objective of this study was to study the misconceptions of parents of primary school children in Riyadh about the use of antibiotics for upper respiratory tract (URT) symptoms; and also study perceptions, attitudes, and behavior toward antibiotic use and identifies the factors affecting this.

Methods: Analytic cross sectional study of parents in one large city: Riyadh, Saudi Arabia. Study population were parents of children studying in these schools, and were selected multistage sampling and proportional to population size (PPS).

Results: The questionnaire was distributed to 1306 parents. The response rate was $78.9 \%, 56.6 \%$ respondents were mothers with a mean age of $40 \pm 7$. Sixty seven percent of the parents admitted to self-prescription once or more, and the most common reason for self-prescribing, was because they thought the child was not ill enough to be taken to hospital $(41.8 \%)$. This was followed by $37.7 \%$ who used "leftovers". Regarding the attitude toward antibiotic prescription, $62.5 \%$ agreed that children should not be given an antibiotic when they have fever and nasal congestion. In addition, $63.5 \%$ agreed that they should give their child antibiotic for ear or throat pain. Around two thirds agreed that upper respiratory tract infection (URTI) was caused by a virus. Those who obtained their information from primary health care centers and general practitioners had the lowest median of total knowledge score, and the highest knowledge was for those who obtained information from websites and the social media. Multiple linear regressions revealed that parents whose incomes were high, had high education, had children in private schools were more likely to have good knowledge and highly favorable attitudes and practices toward antibiotic use.

Conclusion: Thirteen percent had an excellent knowledge, and $52.7 \%$ had an intermediate level of knowledge. Of those with excellent knowledge, 58.6\% still expected to get antibiotic prescription from a physician for URTI.
\end{abstract}

Keywords: Antibiotics, misuse, Saudi Arabia, upper respiratory tract infection

\section{INTRODUCTION}

The World Health Organization (WHO) defines self-medication as treating one's own symptoms or those of other family members, especially children ${ }^{(1)}$. Antibiotics misuse has become a global health problem that has led to many serious health issues such as antibiotic resistance. Many authorities consider such practices as incomplete antibiotic course, suboptimal dose, self-prescription, re-use of leftover antibiotics, and inappropriate attitude as the leading causes of the development of antibiotic resistance ${ }^{(2-8)}$. Antibiotics are some of the important medications that are misused for viral respiratory tract infections, to the extent that parents expect antibiotic prescriptions from physicians on the assumption that they will reduce the severity of the symptoms although they really would have no effect on the time course of the disease ${ }^{(9,10)}$. In Saudi Arabia, antibiotics can be purchased from the pharmacy without a prescription ${ }^{(9)}$. Although there has been a law since 1978 forbidding the purchase of antibiotics without prescription, this law is not enforced by pharmacists ${ }^{(11)}$. Finally, information regarding the antibiotic consumption in Saudi Arabia is very limited, and there are no reports on the trends of antibiotic use by Saudi children, especially those with upper respiratory tract infections (URTIs). Consequently, the study of parents' knowledge, practice, and attitude toward this global problem becomes even more important ${ }^{(12)}$. To the best of our knowledge, there is very little data in Saudi Arabia on antibiotic misuse and parents' knowledge, beliefs, and practice. In addition, no studies have been done on parents in the Central Province ${ }^{(9)}$. The current study was conducted to assess parents' knowledge and awareness of antibiotic use for the upper respiratory tract symptoms (URTI) in the Central Province, Saudi Arabia. 


\section{METHODS}

This cross-sectional study was conducted in governmental and private primary schools in Riyadh city, Central Province, Saudi Arabia. The study population was parents (Saudi and expatriate) of children from first to sixth grades, resident in Riyadh. All guardians other than parents were excluded. Thirteen schools were randomly chosen by a proportional allocation from the frames of 89 private schools and 114 governmental schools. A total of 1306 parents were approached, and 1030 parents completed the questionnaire giving a response rate of $78.9 \%$. Six private and seven governmental schools were chosen giving a total of thirteen schools. A stratified random sampling and proportional allocation of schools were used from all the districts to cover all social classes of the community. The data were collected using a structured, self-administered of recent literature and similar questionnaires based on the objectives of the study. On the first page of the six parts questionnaire was an introductory statement on the purpose of the study and an appreciation to the parents for their participation, the name of the investigator, and the method of contact. The second part of the questionnaire questions 1-8 elicited demographic characteristics. Questions 9-10 were multiple response questions: asking whether they expected the doctor to prescribe for the upper respiratory tract infections and what symptoms would make them go to the doctor. The second part (question 11-17) assessed parents' attitude to antibiotic use for common upper respiratory tract symptoms; part 3 (questions 18-23) assessed knowledge of URTI in the study population, part 4 (questions 24-32) assessed the perception of the study population of antibiotics use for URTI, part 5 (questions 33-41) was on self-prescription of antibiotics and possible factors associated with it; part 6 (question 42-50) measured health behavior of the study population on requesting antibiotic prescriptions from their physicians. Questions on knowledge were assessed using scale 1-3 (1 = agree, 2 = I don't agree, and $3=$ I don't know). The questions on beliefs and practices toward antibiotics resistance were scored on a scale of mostly $=1$, sometimes $=2$, never $=3$. The participants were requested to respond to questions according to their own awareness of the subject. The scoring system used gave the value of one for each correct response, and a zero for the wrong response. Knowledge score was calculated as percentage of correct answers. The knowledge score of $\leq 40 \%$ was considered poor; intermediate knowledge was a score of $41<70 \%$; and good knowledge was a score of $70 \%$ and above. A pilot study was conducted on 30 parents - different from the target group to check understanding and applicability of the questionnaire. The researchers reviewed the questionnaire before and after the pilot study. Based on the results, some linguistic and technical modifications of questions were made to remove any ambiguity and make them easy to understand and interpret. The questionnaire was validated after modification and reviewed by 3 faculty members. The revised questionnaires were scrutinized and the necessary changes made before the final approval by the reviewers. The questionnaires were sent to the participants through their children in the schools. Data were coded, entered, and analyzed in a personal computer using Statistical Package for Social Sciences (SPSS) software version 20 (The collected data were coded, entered, and analyzed using statistical package for the Social Science Version 16.0, SPSS Inc. Released 2007. SPSS for windows, Version16.0 Chicago). Internal consistency was checked, Cronbach's alpha was $>0.751$, which is considered acceptable. Data were presented using descriptive statistics in the form of frequencies and percentages for qualitative variables and mean and standard deviation, range, and quartiles for quantitative variables. Chi-square test, Mann-Whitney Z test, Kruskal Wallis, and logistic regression analysis were used as appropriate to determine association. The study was approved by the Ethical Committee of King Khalid University Hospital (KKUH).

\section{RESULTS}

The study population comprised 1030 parents of primary school children. Almost $30 \%$ of the schools were private; $56.6 \%$ of the questionnaires were filled by the mothers of the children, and $43.4 \%$ by the fathers in the sample; the mean age of the respondents was $40 \pm 7$ years. Socio-demographic characteristics of the respondents are shown in Table 1. Knowledge score percent of antibiotic in URTI ranged from $0 \%$ to $100 \%$ with a median of $46.6 \%$. More than half $(53 \%)$ of the parents were thought to have intermediate knowledge, $34 \%$ poor knowledge, and only $13 \%$ had good knowledge scores [Figure 1]. A good percentage answered correctly by saying there was no need to take an antibiotic for nasal congestion and fever (62.5\%) and $(74 \%)$, respectively. A lower percentage (26\%) had good knowledge with regard to throat pain and (39.4\%) as regards earache. Although more than half of the respondents $(61 \%)$ correctly believed that URTI was caused by a virus, only one fifth of them knew that URTI was self-limiting; only $20 \%$ agreed that URTI was not quickly resolved with the use of antibiotic [Figure 2]. Figure 3 shows the parents' correct perceptions in antibiotics prescription. Overall, most of 
the answers were correct except that a high percentage $(81.2 \%)$ of parents believed the use of antibiotics prevented complications of URTI. It is noteworthy that $58.6 \%$ of those considered as having excellent knowledge still expected to get antibiotics prescriptions from a physician for URTI. Higher knowledge scores for those parents whose children were in private than in governmental $(\mathrm{P}=0.0001)$ schools, for parents with higher incomes ( $\mathrm{P}=0.001)$, Saudi more than nonSaudi parents $(\mathrm{P}=0.034)$, married more than divorced, or widowed parents $(\mathrm{P}=0.047)$. In addition, the higher the education the higher the knowledge score was $(\mathrm{P}=0.001)$. These differences were statistically significant. Fifty seven percent of the parents reported self-prescribing an antibiotic once or more times for their children. The most common reason given was that they thought the child was not ill enough to be taken to hospital. Next was the use of left - over medication and the least was the advice of a relative or friend [Figure 4]. Concerning different parent behaviors with regard to asking for a prescription for an antibiotic from physicians, almost half of the parents mentioned they had done this once or more, and about $17 \%$ said they had insisted on it. Almost $20 \%$ of the physicians prescribed antibiotics just because the parents had asked them to. In $43 \%$ of cases, the doctor had explained the disease and the need for an antibiotic, while $16.3 \%$ of the parents claimed that the physician had never done this. About $80 \%$ mentioned that they never used leftover antibiotic to treat URTI symptoms Table 2 . The major sources for information on the use of antibiotic in URTIs were other physicians and PHC physicians followed by website and pamphlets while the less common sources included previous experience, social media, friends, and relatives [Table 3]. The highest knowledge scores were observed from those whose information was based on previous experience, from websites and the social media. The lowest median score percent of knowledge was from those who obtained their information from primary health care (PHC) centers and general practitioners [Table 3]. After entering the factors that had statistically significant association with higher knowledge scores by bivariate analyses (Type of school, Nationality, Educational level, Job, and Income) into multiple linear regression models, the only independent significant factors resulting were children in private schools, parents with a diploma or higher level of education, and high incomes [Table 4].
Table (1): Sociodemographic characteristics of parents of primary school children in Eastern Province, Kingdom of Saudi Arabia. $(n=1030)$.

\begin{tabular}{|l|c|}
\hline \multicolumn{1}{|c|}{ Characteristic } & $\mathbf{N}(\%)$ \\
\hline Respondent & $447(43.4)$ \\
Father & $583(56.6)$ \\
Mother & $40 \pm 7$ \\
Age (years), mean \pm SD & $700(73.8)$ \\
\hline Nationality & $248(26.2)$ \\
Saudi & \\
Non-Saudi & $912(88.8)$ \\
\hline Marital status & $96(9.3)$ \\
Married & $19(1.9)$ \\
Divorced & $4.2 \pm 1.8$ \\
Widowed & $13(1.3)$ \\
Kids number (mean \pm SD) & $19(1.8)$ \\
\hline Education level & $46(4.5)$ \\
Illiterate & $98(9.5)$ \\
Read and write & $334(32.5)$ \\
Elementary & $519(50.4)$ \\
Intermediate & \\
Diploma or high school & $90(20.7)$ \\
Bachelor's degree or higher & $89(20.5)$ \\
\hline Father's job & $173(39.9)$ \\
Civilian & $38(8.8)$ \\
Military & $30(6.9)$ \\
Private sector & $2(0.5)$ \\
Private business & \\
Retired & $343(59.7)$ \\
Unemployed & $94(16.3)$ \\
\hline Mother's job & $100(17.4)$ \\
Homemakers & $15(2.6)$ \\
Civilian & $9(1.6)$ \\
Private sector & $194(22.1)$ \\
Private business & $321(36.6)$ \\
Retired & $363(41.3)$ \\
\hline Salary (SR) & \\
55000 & \\
From 5000 to 9999 & \\
$\geq 10,000$ & \\
\hline SD Standard & \\
\hline & \\
\hline
\end{tabular}

$\mathrm{SD}=$ Standard deviation

Table 2: Health behavior of parents of primary school children in Eastern Province regarding asking antibiotic prescription from their physicians $(\mathrm{n}=1030)$.

\begin{tabular}{|l|c|c|c|}
\hline \multicolumn{1}{|c|}{ Behavior in antibiotics prescribing } & $\begin{array}{c}\text { Mostly } \\
\text { \% }\end{array}$ & $\begin{array}{c}\text { Sometimes } \\
\text { \% }\end{array}$ & $\begin{array}{c}\text { Never } \\
\text { \% }\end{array}$ \\
\hline $\begin{array}{l}\text { Ever asked the doctor if necessary to } \\
\text { prescribe antibiotic for your child }\end{array}$ & $46.7^{*}$ & 35.0 & 18.3 \\
\hline $\begin{array}{l}\text { Ever asked the doctor to prescribe } \\
\text { antibiotic for your child }\end{array}$ & 11.1 & 37.2 & $51.6^{*}$ \\
\hline $\begin{array}{l}\text { Ever insisted that doctor prescribe an } \\
\text { antibiotic for your child }\end{array}$ & 5.5 & 10.9 & $83.6^{*}$ \\
\hline $\begin{array}{l}\text { Doctor explain to you the disease and } \\
\text { necessity or not to prescribe antibiotic }\end{array}$ & $43.2^{*}$ & 40.5 & 16.3 \\
\hline $\begin{array}{l}\text { Doctor prescribed for your child } \\
\text { because you asked }\end{array}$ & 5.6 & 13.4 & $81.1^{*}$ \\
\hline $\begin{array}{l}\text { Ever thought of changing doctors } \\
\text { because mine did not prescribe } \\
\text { antibiotics for my child when I asked }\end{array}$ & 7.6 & 18.9 & $73.5^{*}$ \\
\hline $\begin{array}{l}\text { Ever considered changing your doctor } \\
\text { because you felt he was over- } \\
\text { prescribing antibiotics for your child }\end{array}$ & $15.3^{*}$ & 29.6 & 55.1 \\
\hline $\begin{array}{l}\text { Ever used leftover to treat URTI } \\
\text { symptoms }\end{array}$ & 5.7 & 14.4 & $79.8^{*}$ \\
\hline
\end{tabular}

*Correct behavior. URTI = Upper respiratory tract infection 
Table (3): Source of information and knowledge score percentage for antibiotic use in upper respiratory tract infections by main source of information.

\begin{tabular}{|l|c|c|}
\hline \multicolumn{1}{|c|}{$\begin{array}{c}\text { Main source of } \\
\text { information }\end{array}$} & $\mathbf{N}(\%)$ & Median knowledge score \\
\hline Previous experience & $63(6.3)$ & 55.6 \\
\hline Websites & $329(32.8)$ & 48.9 \\
\hline Social media & $137(13.6)$ & 48.9 \\
\hline Other physicians & $498(49.6)$ & 46.7 \\
\hline Pamphlets & $320(31.9)$ & 46.7 \\
\hline Relatives & $237(23.6)$ & 46.7 \\
\hline Friends & $157(15.6)$ & 46.7 \\
\hline Newspapers/magazines & $81(8.1)$ & 46.7 \\
\hline PHC and physicians & $441(43.9)$ & 40 \\
\hline
\end{tabular}

Each parent may have more than one response. $\mathrm{PHC}=$ Primary health care

Table (4): Multiple linear regressions for factors associated with higher knowledge score.

\begin{tabular}{|l|c|c|c|c|c|}
\hline & \multicolumn{2}{|c|}{$\begin{array}{c}\text { Unstandardized } \\
\text { coefficients }\end{array}$} & $\begin{array}{c}\text { Standardized } \\
\text { coefficients }\end{array}$ & \multirow{2}{*}{ t } & \multirow{2}{*}{ p-Value } \\
\cline { 2 - 4 } & $\mathbf{B}$ & SE & Beta & & \\
\hline $\begin{array}{l}\text { Constant } \\
\text { Kids in } \\
\text { private } \\
\text { schools }\end{array}$ & 32.965 & 2.023 & & 16.297 & 0 \\
\hline $\begin{array}{l}\text { Diploma or } \\
\text { higher } \\
\text { education }\end{array}$ & 11.084 & 1.355 & 0.084 & 2.687 & 0.007 \\
\hline $\begin{array}{l}\text { High } \\
\text { income }\end{array}$ & 4.932 & 1.300 & 0.118 & 3.793 & $<0.0001$ \\
\hline
\end{tabular}

$\mathrm{F}=32.986, \mathrm{P}=0.0001, \mathrm{R} 2=8.8 \% . \mathrm{SE}=$ Standard error

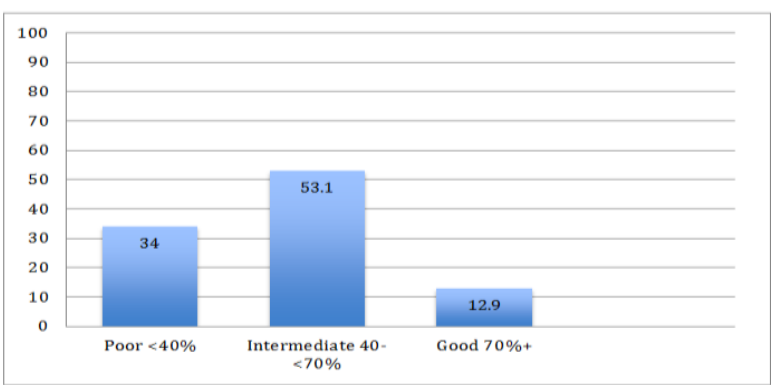

Figure (1): Total knowledge score percent about antibiotic use in the upper respiratory tract infection

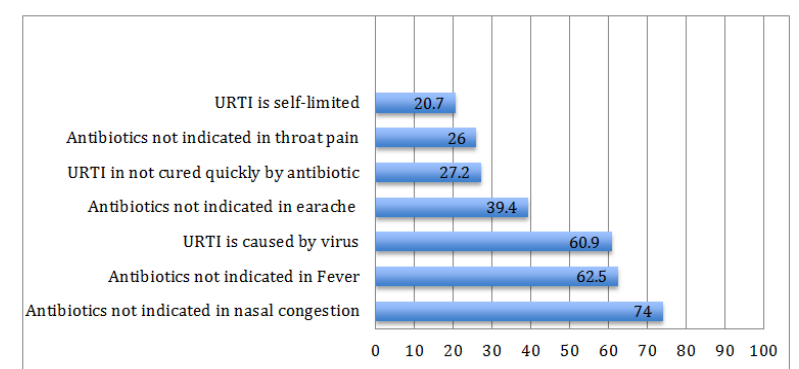

Figure (2): Distribution of patients' correct answer about indication for antibiotic prescription for common upper respiratory tract infection symptoms

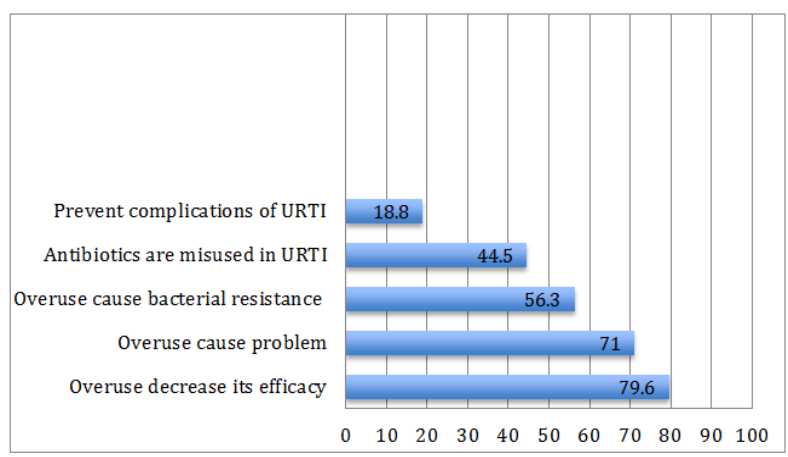

Figure (3): Distribution of patients' correct perceptions regarding antibiotics in the upper respiratory tract infection

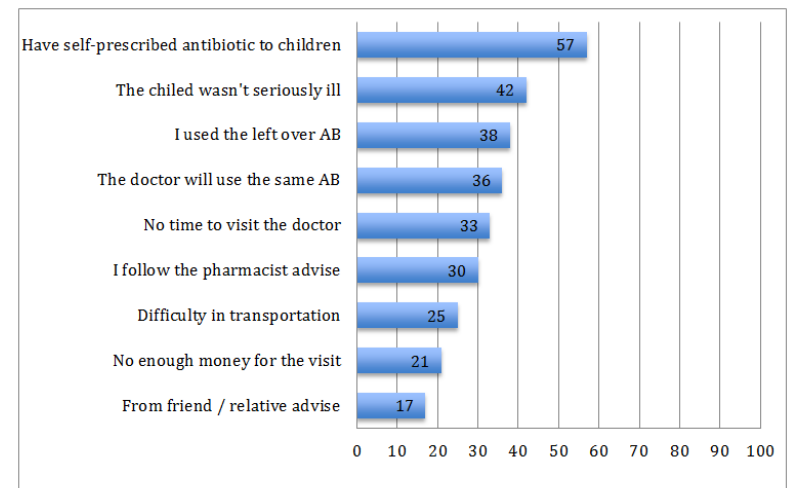

Figure (4): Self-prescription and reasons for Selfprescription of antibiotics by parents (percentage calculated from total cases)

\section{DISCUSSION}

The association of demographic data with knowledge of antibiotic use was further assessed by doing the bivariant analysis. Lower educational level of parents, children in the governmental schools, and lower income of parents were associated with a poorer knowledge. Other studies also depicted results in which there was less knowledge among parents with low educational attainment ${ }^{(3,7,9,13,17)}$, and lower income as seen in studies done in Riyadh, Vietnam, and Greece ${ }^{(7,9,16)}$. In Saudi Arabia as in many Middle East countries, antibiotics can be purchased without prescription, that is why there is a high percentage of parents in our study who self-prescribe antibiotics (56.9\%). A recent community based systematic review that assessed antibiotic misuse of the adult and pediatric populations in Saudi Arabia showed a prevalence of $41 \%-92 \%{ }^{(23)}$. Similar percentages had been reported in Jordan $40 \%{ }^{(19,20)}, 45 \%$ in Abu Dhabi, ${ }^{(21)} 57 \%$ in Syria ${ }^{(17)}$, and much higher in others; $85 \%$ in Egypt ${ }^{(23)}$, from $60 \%-78 \%$ in Yemen ${ }^{(24,25)}$ and about $74 \%$ in Sudan. In Europe, $80 \%$ of Greek 
parents admitted that URTI is self-limiting, which is far higher than our result $(20.7 \%)$; only $10 \%$ self-prescribe antibiotics. In our study, throat pain was the most common reason for parents to expect antibiotic prescriptions $(63.5 \%)$, followed by an earache (44\%). The results of questions on selfprescription in some studies were similar revealing that throat pain was the most common reason $(4,9,13,20)$, but other symptoms such as fever ${ }^{(5,7)}$ were reported as higher in some other studies; earache ${ }^{(14)}$, common cold ${ }^{(3)}$, and cough ${ }^{(3)}$. Most of these symptoms that compel parents to self-prescribe are viral in origin, indicating a questionable attitude to prescriptions that can lead to Antimicrobial resistance. Around two-thirds of the parents did not think that URTI was self-limiting and (60.9\%) agreed it was caused by viruses. Similar results were obtained in Riyadh $(68.6 \%){ }^{(9)}$. More than half of the respondents agreed that antibiotic overuse caused bacterial resistance and a good percentage $(71 \%)$ agreed that overuse caused a problem. A similar percentage was seen in the public in Hong Kong ${ }^{(7)}$. A high percentage $(59.7 \%)$ believed that URTI could be cured quickly with an antibiotic. Similar results were obtained in various studies ${ }^{(9,14,15)}$, but half of this percentage $(24.7 \%)$ was obtained in Greece ${ }^{(22)}$. Of the respondents, $75.9 \%$ wanted to be better informed on the use of antibiotics. Four-fifths of our parents expected an antibiotic prescription (79.9\%) once the child developed URTI symptoms. There were similar expectations from Greek parents ${ }^{(22)} ; 72.9 \%$ expected antibiotics with an antipyretic or painkillers (half of them expected cough syrup and one-fourth anticipated an antihistamine to be given. Around half of the parents, requested antibiotic prescriptions once or more times from the doctor; there were similar findings in other studies ${ }^{(15)}$. In our study, $56.9 \%$ admitted to self-prescribing an antibiotic for their child once or more times. In Riyadh, the capital of Saudi Arabia a similar study showed that only $11.6 \%$ of parents self-prescribed an antibiotic. This was very low compared to other studies done in Gulf countries. One of the reasons could be a selection bias as the author mentioned that the survey was done in 4 malls, so could not be a good representation ${ }^{(9)}$.

The most common reason given for selfprescription by parents is that they thought the child was not ill enough to be taken to hospital $(41.8 \%)$. This was followed by the use of "leftovers" (37.7\%), knew the doctor would prescribe the same antibiotics (35.6\%), had no time to go to the doctor's (32.8\%), and followed the pharmacist's advice (30.4\%). In Ankara, the three most common reasons for self-medication was the use of leftover medication; not having the time to go to the physician, and not wanting to pay for the visit ${ }^{(4)}$. In Vietnam, mothers often self-medicated when they thought the child was not ill enough to be taken to hospital ${ }^{(6)}$. Other less common factors included problems with transportation $(25.1 \%)$ not having enough money to go to the doctor (20.8\%) and taking the advice of a friend or relative (16.7\%). A good percentage of parents $(73.5 \%)$ never considered changing doctors because he did not prescribe antibiotics when they requested. Similar high results were obtained in Cyprus while $18.9 \%$ admitted the doctor prescribed an antibiotic because they had asked him to and in the same study in Cyprus; the percentage was less $(4.5 \%){ }^{(14)}$. This finding showed a good relationship between the parents and the doctors since $73.5 \%$ never considered changing doctors because the doctor did not prescribe antibiotics when requested. In addition, $83.6 \%$ never persisted. It shows that the parents did not easily sway the physicians; about $81.1 \%$ never prescribed the antibiotic because the parents ask for it. A good percentage (83.7\%) admitted the doctor usually or sometimes explained the nature of the disease to them and the need or not to prescribe antibiotic. The main source of information on antibiotics was from physicians (49.6\%) followed by PHC centers (43.9\%), websites $(32.8 \%)$. This result was similar to other studies in which the main source of information was the physician ${ }^{(13,14,15)}$. On the other hand, studies conducted in countries with easy access to antibiotics in pharmacies showed that the main sources of antibiotics were through the pharmacist and leftover medications $(3,7,9,20,21,23)$. A comparison of the mean percentage score on knowledge about antibiotic in relation to the main source of information in antibiotic use shows that the lowest score on knowledge of URTI was among those who obtained their information from PHC. When the same questions on antibiotics were asked, in general, those who obtained their information from PHC or relatives had the lowest score. Saudi parents have confidence in their physicians, but the main source of knowledge came from PHCs, especially for parents of governmental school children, who as mentioned previously, had fewer correct answers. This indicates that more time needs to be spent in educating the staff in PHCs on antibiotic use to reduce unnecessary prescriptions. This was also the conclusion arrived at in 
a study done in Greece. The literature review revealed that availability of medical insurance was associated with better knowledge and less antibiotic misuse. However, since medical care is free for all citizens in Saudi Arabia, this may not be considered a factor ${ }^{(9)}$.

\section{RECOMMENDATIONS}

We need to emphasize the importance of health education, especially for parents of children in governmental school, those who have little education and those who have little income. All health-care providers in the PHC centers must provide accurate information about antibiotics to patients. We also recommend that physicians be trained to follow an approach whereby they examine, explain, reassure, and advise rather than simply prescribe antibiotics. Parents should be guided on when to bring a child with symptoms of URTI to PHC/hospital, enlightened on the benign course of the disease and the impact of antibiotic resistance on health and community. There should be public campaigns to increase the awareness of antibiotic use, and improve the doctor-patient relationship and the involvement of patients in the treatment plan. The Saudi government should ban the purchase of antibiotics without prescriptions.

\section{REFERENCES}

1. World Organization Health (2000): Guidelines for the Regulatory Assessment of Medicinal Products for use in Self-Medication. Available at: http://apps.who.int/medicinedocs/pdf/s2218e/s221 8e.pdf

2. WHO (2001): WHO Global Strategy for Containment of Antimicrobial Resistance. WHO/CDS/CSR/DRS/2001.2 Switzerland: World Health Organization, Communicable Disease Surveillance and Response. Available at: http://www.who.int/csr/resources/publications/dru gresist/en/EGlobal_Strat.pdf

3. Togoobaatar G, Ikeda N, Ali M, Sonomjamts M, Dashdemberel S, Mori $\mathrm{R}$ et al. (2010): Survey of non-prescribed use of antibiotics for children in an urban community in Mongolia. Bull World Health Organ, 88:930-6.

4. Ilhan MN, Durukan E, Ilthan SO, Aksakal FN, Ozkan S, Bumin MA et al. (2009): Selfmedication with antibiotics: Questionnaire survey among primary care center attendants. Pharmacoepidemiol Drug Saf., 18:1150-7.
5. Skliros E, Merkouris P, Papazafiropoulou A, Gikas A, Matzouranis G, Papafragos C et al. (2010): Self-medication with antibiotics in rural population in Greece: A cross-sectional multicenter study. BMC Fam Pract., 11:58.

6. Le TH, Ottosson E, Nguyen TK, Kim BG, Allebeck P (2011): Drug use and self-medication among children with respiratory illness or diarrhea in a rural district in Vietnam: A qualitative study. $\mathrm{J}$ Multidiscip Healthc., 4:329-36.

7. You JH, Yau B, Choi KC, Chau CT, Huang QR, Lee SS et al. (2008): Public knowledge, attitudes and behavior on antibiotic use: A telephone survey in Hong Kong. Infection, 36:153-7.

8. Kardas P, Devine S, Golembesky A, Roberts C (2005): A systematic review and meta-analysis of misuse of antibiotic therapies in the community. Int J Antimicrob Agents, 26:106-13.

9. Abobotain AH, Sheerah HA, Alotaibi FN, Joury AU, Mishiddi RM, Siddiqui AR et al. (2013): Socio-demographic determinants of antibiotic misuse in children. A survey from the central region of Saudi Arabia. Saudi Med J., 34:832-40.

10. Harnden A, Perera R, Brueggemann AB, Mayon-White R, Crook DW, Thomson A et al. (2007): Respiratory infections for which general practitioners consider prescribing an antibiotic: A prospective study. Arch Dis Child., 92:594-7.

11. Bawazir SA (1993): Prescribing patterns of ambulatory care physicians in Saudi Arabia. Ann Saudi Med., 13:172-7.

12. Alumran A, Hurst C, Hou $X$ (2011): Antibiotics overuse in children with upper respiratory tract infections in Saudi Arabia: Risk factors and potential interventions. Clin Med Diagn., 1:8-16.

13. Napolitano F, Izzo MT, Di Giuseppe G, Angelillo IF (2013): Public knowledge, attitudes, and experience regarding the use of antibiotics in Italy. PLoS One, 8:e84177.

14. Rousounidis A, Papaevangelou V, Hadjipanayis A, Panagakou S, Theodoridou M, Syrogiannopoulos G et al. (2011): Descriptive study on parents' knowledge, attitudes and practices on antibiotic use and misuse in children with upper respiratory tract infections in Cyprus. Int $\mathbf{J}$ Environ Res Public Health, 8:3246-62. 
15. Yu M, Zhao G, Stålsby Lundborg C, Zhu Y, Zhao Q, Xu B et al. (2014): Knowledge, attitudes, and practices of parents in rural China on the use of antibiotics in children: A cross-sectional study. BMC Infect Dis., 14:112.

16. Panagakou SG, Papaevangelou V, Chadjipanayis A, Syrogiannopoulos GA, Theodoridou M, Hadjichristodoulou CS et al. (2012): Risk factors of antibiotic misuse for upper respiratory tract infections in children: Results from a cross-sectional knowledge attitude practice study in Greece. ISRN Pediatr., 2012:685302.

17. Elberry AA, Shaikh A, Al-Marzouki J, Fadul R (2012): Evaluation of non-prescribed antibiotic use among children with upper respiratory tract infection. IRJPP., 2:147-52.

18. Alnemri AR, Almaghrabi RH, Alonazi N, Alfrayh A (2016): Misuse of antibiotic: A systemic review of Saudi published studies. Curr Pediatr Res., 20:169-73.

19. Al-Azzam SI, Al-Husein BA, Alzoubi F, Masadeh MM, Al-Horani MA (2007): Selfmedication with antibiotics in Jordanian population. Int J Occup Med Environ Health, 20:373-80.

20. Sawair FA, Baqain ZH, Abu Karaky A, Abu Eid R (2009): Assessment of self-medication of antibiotics in a Jordanian population. Med Princ Pract., 18:21-5.
21. Abasaeed A, Vlcek J, Abuelkhair M, Kubena A (2009): Self-medication with antibiotics by the community of Abu Dhabi Emirate, United Arab Emirates. J Infect Dev Ctries., 3:491-7.

22. Barah F, Gonçalves V (2010): Antibiotics use and knowledge in the community in Kalamoon, Syrian Arab Republic: A cross-sectional study. East Mediterr Health J., 16:516-21.

23. Aboul Fotouh AM, el-Damaty SE, Abdel Megeid FY (1998): Mother's knowledge about antibiotic and role of self prescription. J Egypt Public Health Assoc,. 73:57-69.

24. Mohanna M (2010): Self-medication with antibiotic in children in Sana'a City, Yemen. Oman Med J., 25:41-3.

25. Belkina T, Al Warafi A, Hussein Eltom E, Tadjieva N, Kubena A, Vlcek J et al. (2014): Antibiotics use and knowledge in the community of Yemen, Saudi Arabia, and Uzbekistan. J Infect Dev Ctries., 8:424-9. 